\title{
Topical Silver Diamine Fluoride 38\% for Arresting Dentine Caries Active in Dental Clinic
}

\author{
Poppy Andriany ${ }^{1,2, *}$ Sondang Pintauli ${ }^{3}$, Rahayu Lubis ${ }^{4}$, Anton Rahardjo ${ }^{5}$ \\ ${ }^{1}$ Doctoral Program Student, Faculty of Dentistry, Universitas Sumatra Utara, Indonesia \\ ${ }^{2}$ Department of Preventive and Public Health Dentistry, Faculty of Dentistry, Universitas Syiah Kuala, Indonesia \\ ${ }^{3}$ Department of Preventive and Public Health Dentistry, Faculty of Dentistry, Universitas Sumatera Utara, Indonesia \\ ${ }^{4}$ Department of Epidemiology, Faculty of Public Health, Universitas Sumatera Utara, Indonesia \\ ${ }^{5}$ Department of Preventive and Public Health Dentistry, Faculty of Dentistry, Universitas Indonesia, Indonesia \\ *Corresponding author.Email: poppyfaza@unsyiah.ac.id, sondangp@yahoo.com, rahayu_lubis@yahoo.com, \\ antonrahardjo@gmail.com
}

\begin{abstract}
Introduction. This study aimed the effectiveness of topical silver diamine fluoride application in arresting active dentine caries in primary teeth in dental clinic.Methods. This study was a clinical trial, A total of 40 children aged 5-6 years old in dental clinic who had at least one active dentine caries lesion in the primary molar teeth participated in this study. 66 tooth with active dentine caries received treatment SDF 38\% at baseline and . Follow-up examinations were conducted at 3 months after baseline. Results., the total caries arrest rates at tooth in dental clinic were $88.7 \%(p=0.004)$. The statistical analysis by $\mathrm{t}$ test showed that the SDF $38 \%$ application arrest of dentine caries in primary teeth of children had a significant difference between the percentage of caries subjects treated with SDF $38 \%$ after 3 months evaluation when compared to the baseline ( $p<0.05$ ). Conclusion. Topical $38 \%$ silver diamine fluoride is effective and safe in arresting caries dentine active in primary teeth of children in dental clinic.
\end{abstract}

Keywords: Silver Diamine Fluoride, Caries arrest, Children, Dental clinic

\section{INTRODUCTION}

International data on caries epidemiology stated that dental caries is a disease that is susceptible to occur in the age of children in developing and developed countries [1]. The results of the study in the city of Manado showed that the prevalence of deciduous caries in primary school children aged 3-6 years in Malalayang district reached $90 \%$ with an average def-t index of 6.99 which meant that on average each child had 7 teeth that had primary teeth caries [2].

Remineralization of carious lesions with minimally invasive treatment in dental practice by arresting active caries is strongly promoted which is the basic oral care package [3]. Among these methods, application of topical silver Diamine Fluoride 38\% (SDF 38\%) can arrest caries [4]. Silver Diamine Fluoride $38 \%$ is a carious treatment ingredient which is often referred to as the Arresting Caries Treatment (ACT) method, which is the management of dental caries in children that are treated only by arresting the process of caries development. A concentration of $38 \%(44,800 \mathrm{ppm}$ fluoride ions) is commonly used to arrest the caries in primary teeth. The use of SDF $38 \%$ is a non-invasive procedure that is quick and easy to use [5].

A number of clinical studies have shown that dental caries in children could be arrested by using topical silver diamine fluoride. Collagen is a dentin supporting structure that binds apatite crystals together. Detached collagen is seen in active dentinal lesions in the hydroxyapatite structure, triggering the demineralization of the dentine [6,7]. Silver Diamine Fluoride $38 \%$ can increase mineral density in enamel caries lesions and micro hardness in dentine caries lesions. An important component of dental tissue will react with SDF $38 \%$ to form calcium fluoride which has a protective effect against caries [5]. The purpose of this study was to determine the effectiveness application of SDF $38 \%$ in children aged 5-6 years who have active dentin caries in primary molars in dental clinics.

\section{METHODS AND MATERIALS}

The implementation of the study had received approval from the health research ethics committee of the Faculty of Medicine, University of North Sumatra 
(No. 27 / TGL / KEPK FK USU-RSUP HAM / 2018). The type of this research was a clinical trial, the study was conducted at a pediatric dental clinic at Rumah Sakit Gigi dan Mulut (RSGM) Universitas Syiah Kuala, Banda Aceh City. Research subjects were children aged 5-6 years who came to the pediatric dental clinic at RSGM Unsyiah Banda Aceh. Two examiners were calibrated for the examination of active dentin caries, with kappa values of 0.836 and 0.881 with $\mathrm{p}$ values of $<0.001$.

Intervention of $38 \%$ SDF fluid application was carried out on active dentin caries teeth in primary molars with the aim of measuring the effect of these interventions that caused dental caries to arrest, which was previously predicted. The inclusion criteria for participants who participated in this study were children who had active dentin caries at least 1 molar tooth surface, parents willed to participate in the study for 3 months and signed an informed consent. Clinical examination of active dentin caries was characterized by the presence of soft tissue surfaces on dentin surface, showed active or inactive dentin caries (ICDAS code 5) [8].

Application technique of $38 \%$ SDF started with tooth surface prophylaxis from debris by using wet gauze, saliva was ejected by using suction so that the work area was not wet, the tooth surface was dried, soft tissue was protected by using veseline, apply $38 \%$ SDF to the tooth surface by using a micro brush, let SDF $38 \%$ absorbed for up to 3-4 minutes. The children was instructed not to eat and drink for 1 hour after $38 \%$ SDF application. After 3 months SDF 38\% evaluation and clinical examination of caries were arrested. Caries arrested in dentin were clinically determined by the harden of dentin surface and were yellow to black staining of caries lesions treated by SDF 38\% [9].

\section{RESULTS}

Table 1. Characteristics of children $(n=40)$

\begin{tabular}{ccc}
\hline Variable & $\mathbf{n}$ & $(\%)$ \\
\hline Children's age & & \\
5 & 17 & 42.5 \\
6 & 23 & 57.5 \\
Children's gender & & \\
Male & 19 & 47.5 \\
Female & 21 & 52.5 \\
\hline
\end{tabular}

Table 1 showed that the highest number of child subjects was the age of 6 years by $57.5 \%$, while the age of 5 years was $42.5 \%$. Male respondents were $47.5 \%$ and female were $52.5 \%$.
Table 2. Number of respondents who had active dentin caries before and after SDF application

\begin{tabular}{ccc}
\hline Before & \multicolumn{2}{c}{ After } \\
\hline Active dentin caries & Arrested & Active \\
\hline 40 & 37 & 3 \\
& $(92.5 \%)$ & $(7.5 \%)$ \\
\hline
\end{tabular}

Table 2 showed the percentage of participants who experienced active dentin caries before and after SDF application 38\%. Before the SDF 38\% application was obtained as many as 40 participants. After 3 months of SDF $38 \%$ application, 3 children were still experiencing active dentin caries.

Table 3. Number of teeth with active dentin caries before and after 3 months of evaluation

\begin{tabular}{cccc}
\hline Before & \multicolumn{2}{c}{ After } & $\begin{array}{c}P \\
\text { value (B vs } \\
3)\end{array}$ \\
\cline { 1 - 2 } $\begin{array}{c}\text { Active dentin } \\
\text { caries }\end{array}$ & Arrested & Active & \\
\hline 66 & 62 & 4 & 0.001 \\
& $(93.9 \%)$ & $(6.1 \%)$ & \\
\hline
\end{tabular}

Table 3 showed the percentage of the number of 66 primary molars were obtained. The statistical analysis by $\mathrm{t}$ test, showing a significant difference between the percentage of caries subjects treated with SDF 38\% after 3 months evaluation when compared to the baseline $(\mathrm{p}<0.05)$. The analysis showed that there was a significant difference in caries being arrested after evaluation of 3 months SDF 38\% application in subjects at the dental clinic p 0.000 .

\section{DISCUSSION}

Participants who participated in this study were children aged 5-6 years. There were 40 children with active dentin caries. After 3 months of $38 \%$ SDF application, 3 children were still experiencing active dentin caries. This study was in line with previous research which stated that the application of SDF 38\% was effective in arresting active caries after 3 to 10 months of application, where SDF $38 \%$ has a good potential solution for children who had dental complaints [10]. Caries that reactivate after SDF 38\% was applied to a child's teeth, were thought to occur due to the child ate and drank immediately after being smeared with SDF 38\% even though he had been told not to eat, drink, rinse or brush his teeth for 1 hour after SDF 38\% application.

The percentage of the number of teeth that had arrested after being smeared with SDF was $93.9 \%$. There were still caries that reactivated after the application of SDF $38 \%$ because it could be influenced by the anatomical shape of the posterior teeth that had 
pits and fissures, as well as more grooves in comparison to anterior teeth, so that more plaques were retained in posterior teeth and was blocked by unclean plaque despite after brushing teeth. This was in line with previous research that SDF $38 \%$ was more effective in arresting dentin caries in anterior primary teeth [11].

Significant changes in active caries which being arrested after 3 months of SDF $38 \%$ application showed an effectiveness of $38 \%$ SDF in treating active dentin caries in primary teeth. This research was conducted on active dentin caries because SDF $38 \%$ could eliminate sensitive taste and arrested the caries. Topical application of SDF $38 \%$ fluid to the surface of active dentin could form squamous layer and cover dentine tubules and reduce dentin sensitivity. Laboratory studies found that SDF $38 \%$ had a strong antibacterial effect on cariogenic biofilms, and a strong inhibitory effect on the activity of matrix metalloproteinases [12] and cysteine capthesins [13]. Treatment with SDF 38\% can increase the mineral density of enamel caries lesions [14] and microhardness from dentin caries lesions [15]. Silver Diamine fluoride $38 \%$ can inhibit the formation of multi-species cariogenic biofilms in dentin caries lesions and reduce the demineralization process [16]. High concentrations of silver ions in SDF $38 \%$ can affect the physicochemical properties of the structure or morphology of collagen and collagen can be modified into structures that are more resistant to collagen attachment. Healthy collagen consists of calcium and phosphate for precipitation and forming hydroxyapatite [17]. The effect of SDF $38 \%$ occurs in carious lesions not only by the action of fluoride but also by silver ions which react with amino and nucleic acids that inhibit bacterial development [16].

Children who received the SDF 38\% application was found to had many inactive caries and fewer new caries lesions compared to children who did not receive the SDF 38\% application. The recommended frequency of SDF $38 \%$ application to arrest the caries is every six months to once a year [11]. Silver Diamine fluoride which is applied once every six months on the surface of the active dentin caries of primary teeth is found to be more effective in arresting caries than application with glass ionomer [6].

\section{CONCLUSION}

Application of silver diamine fluoride $38 \%$ was effective and safe in arresting active dentin caries in a child's primary molars in a dental clinic.

\section{REFERENCES}

[1] Shalin Shah, et al., 2014. Silver Diamine Fluoride : A Review and Current Applications. J Advanced Oral Research. ; 5 (1).

[2] Christy N.M. 2014. Jurnal Biomedik (JBM) ; 6 (2), 105-9
[3] Frencken JE, Peters MC, Manton DJ, Leal SC, Gordan VV, Eden E. 2012. Minimal intervention dentistry for managing dental caries - a review: report of a FDI task group. Int Dental J ;62:223-43.

[4] Yee R, Holmgren C, Mulder J, Lama D, Walker D., 2009. Efficacy of Silver Diamine Fluoride for arresting caries treatment. J Dent Res; 88: 664-7

[5] Lou YL, Botelho MG, Darvel BW. 2011. Reaction of silver diamine Fluoride with hydroxyapatite and protein., J Dentistry; 39. 612-18.

[6] Zhi QH; Lo EC; Lin HC. 2012. Randomized clinical trial on effectiveness of silverdiamine fluoride and glass ionomer in arresting dentin caries in preschool children. J Dentistry 40: 962-67.

[7] Cao Y, Mei MI, Xu J, Lo EC, Chu CH. 2013. Biomimetic mineralisation of phosphorylated dentine by CPP-ACP. J Dentistry. 41: 818-25.

[8] Pitts NB and KR Ekstrand. 2013. International Caries Detection and Assessment System (ICDAS) and its International Caries Classification and Management System (ICCMS) - methods for staging of the caries process and enabling dentists to manage caries. Community Dent Oral Epidemiol; 41; e41-e52.

[9] Jeremy A Horst, Hellene Ellenikiotis, UCSF Silver Caries Arrest Committee, and Peter M Milgrom. 2016. UCSF Protocol for Caries Arrest Using Silver Diamine Fluoride: Rationale, Indications, and Consent. J Calif Dent Assoc; 44 (1): 16-28[10] Chandra, A Rahardjo, M Adiatman , R Darwita, D A Maharani, and M Callea. 2017. Evaluation of silver diamine fluoride application in children and factors associated with arrested caries survival. J. Phys.: Conf. Ser. 884012118

[10] Braga MM, Mendes FM, De Benedetto MS. 2009. Effect of silver diamine fluoride on incipient caries lession in erupting permanent first molars: pilot study. J Dent Child; 76: 28-33.

[11] Mei ML, Li QL, Chu CH et al. 2012. The inhibitory effects of silver diamine fluoride at different concentrations on matrix metalloproteinases. Dent Mater; 28: 903-8.

[12] Mei ML, Ito L, Cao Y et al. 2014. The inhibitory effects of silver diamine fluorides on cysteine cathepsins. J Dent 42: 329-35.

[13] [Liu BY, Lo EC, Li CM. 2012. Effect of silver and fluoride ions on enamel demineralization: a quantitative study using micro-computed tomography. Aust Dent J; 57: 65-70.

[14] Chu CH, Lo ECM. 2008. Microhardness of dentine in primary teeth after topical fluoride applications. J Dentistry;36:387-91

[15] Mei M.L; Chun H.C; Kan H.L; Ching M.C; Edward C.M.L; 2013. Caries arresting effect of silver diamine on dentin carious lesion with $\mathrm{S}$. mutans and L. acidophilus dual-species cariogenic biofilm. Med Oral Patol Oral Cir Bucal; 18 (6). 824-31.

[16] Mei M.L; L ito; Y Cao; Li Q.L; Edward C.M; Chu C.H; 2013. Inhibitory effect of silver diamine fluoride on dentine demineralisation and collagen degradation. J Dentistry; 41. 809-1 